Arq. Bras. Med. Vet. Zootec., v.68, n.4, p.977-982, 2016

\title{
Caracterização molecular de Cryptosporidium spp. em criações comerciais brasileiras de coelhos
}

[Molecular characterization of Cryptosporidium spp. in Brazilian rabbit farms]

M.M. Heker, A.A. Nakamura, M.V. Meireles*

Universidade Estadual Paulista - Unesp - Araçatuba, SP

\begin{abstract}
RESUMO
A criptosporidiose é uma importante zoonose que pode ser transmitida por meio de alimentos, água de bebida e por contato com animais e pessoas infectadas. Além disso, trata-se de uma enfermidade clínica ou subclínica frequente em diversas espécies de animais, incluindo coelhos domésticos. O objetivo deste estudo foi determinar a ocorrência de Cryptosporidium spp., realizar sua classificação molecular e relacionar a presença do parasito às diferentes fases de criação em 21 criações comerciais de coelhos, localizadas nos estados de Minas Gerais, Mato Grosso do Sul, Pernambuco, Paraná, Rio de Janeiro, Rio Grande do Sul e São Paulo. Quinhentas e catorze amostras de fezes foram colhidas e armazenadas em solução de dicromato de potássio $5 \%$. Os oocistos foram purificados por centrífugo-flutuação em solução de Sheather e visualizados por microscopia, utilizando-se a coloração negativa com verde malaquita. Cinquenta e cinco amostras foram submetidas à reação em cadeia pela polimerase (nested PCR) e ao sequenciamento de fragmentos amplificados, referentes aos genes da subunidade 18S do rRNA e da glicloproteína GP60, visando à caracterização molecular de Cryptosporidium spp. Oito amostras foram positivas para Cryptosporidium spp. pela microscopia $(1,56 \% ; 8 / 514)$ e sete foram positivas pela nested PCR (12,73\%; 7/55). Pela análise molecular, foi possível identificar Cryptosporidium cuniculus (18S rRNA) e C. cuniculus subtipo VbA21 (gp60) em coelhos jovens e em matrizes.
\end{abstract}

Palavras-chave: coelho, coccidiose, classificação molecular, reação em cadeia da polimerase

\begin{abstract}
Cryptosporidiosis is an important zoonotic disease that can be transmitted via water, food and contact with infected animals and people. Furthermore, clinical and subclinical disease occur in many animal species, including the domestic rabbit. The objective of this study was to determine the occurrence of Cryptosporidium spp., perform its molecular classification and correlate the presence of the parasite to the different animal categories in Brazilian rabbits farms. A total of 514 fecal samples from 21 rabbits farms located in the states of Minas Gerais, Mato Grosso do Sul, Pernambuco, Paraná, Rio de Janeiro, Rio Grande do Sul and São Paulo were collected and stored in 5\% potassium dichromate. Fecal samples were purified by centrifugal-flotation in Sheather solution and screened for Cryptosporidium spp. oocysts using the negative malachite green staining. Aiming the molecular characterization of Cryptosporidium spp., nested PCR targeting the 18S rRNA gene and gp60 gene followed by sequencing of amplified fragments were accomplished in 55 samples. Eight samples were positive for Cryptosporidium spp. by microscopy $(1.56 \% ; 8 / 514)$ and seven samples were positive by PCR (12.73\%; 7/55). Molecular analysis revealed Cryptosporidium cuniculus for the $18 S$ rRNA gene and C. cuniculus subtype VbA21 for the gp60 gene in kits and does.
\end{abstract}

Keywords:rabbit, Brazil,coccidiosis, molecular classification, polymerase chain reaction

Recebido em 23 de outubro de 2015

Aceito em 15 de fevereiro de 2016

* Autor para correspondência (corresponding author)

E-mail: marcelo@fmva.unesp.br 


\section{INTRODUÇÃO}

A criptosporidiose é uma importante zoonose que pode ser transmitida por meio de alimentos, água de bebida e por contato com animais e pessoas infectadas. Além disso, trata-se de uma enfermidade clínica ou subclínica frequente em diversas espécies de animais, incluindo coelhos domésticos (Xiao e Fayer, 2008).

$\mathrm{Na}$ África e na Ásia, a criptosporidiose foi considerada a segunda maior causa de diarreia e morte em crianças com menos de cinco anos de idade (Striepen, 2013), sendo responsável por $20 \%$ das causas de diarreia em crianças de países em desenvolvimento (Mosier e Oberst, 2000) e por 748.000 casos anuais de diarreia nos Estados Unidos (Scallan et al., 2011).

Aproximadamente 20 espécies e diversos genótipos de Cryptosporidium já foram encontrados em humanos, incluindo C. hominis, C. parvum, C. meleagridis, C. felis, C. canis, C. cuniculus, C. ubiquitum,C. viatorum, C. muris, C. suis, C. fayeri, C. andersoni, C. bovis, C. scrofarum, C. tyzzeri, $C$. erinacei e os genótipos cavalo, gambá, macaco e esquilo I (Robinson et al., 2008; Xiao e Fayer, 2008; Fayer, 2010; Xiao, 2010; Liuet al., 2014).

Os coelhos eram considerados como o único hospedeiro de C. cuniculus até que um surto de criptosporidiose em humanos por C. cuniculus foi descrito no Reino Unido (Chalmers et al., 2009). A crescente aquisição de coelhos como animais de estimação enfatiza a necessidade de monitoramento de infecções por Cryptosporidium e sua importância em saúde pública (Shiibashi et al., 2006). Os coelhos também podem ser infectados por C. parvum e C. meleagridis, que igualmente são espécies consideradas patogênicas para humanos (Duszynski e Couch, 2013).

Nos coelhos, a infecção por Cryptosporidium muitas vezes não é detectada devido à baixa prevalência e ao fato de que a infecção muitas vezes é subclínica (Shietal., 2010; Zhang et al., 2012). No entanto, quando submetidos a condições estressantes, coelhos portadores de Cryptosporidium podem desenvolver diarreia, cuja gravidade vai depender da idade, da alimentação e do estado imunológico dos animais (Kaupke et al., 2014). A diarreia, associada à criptosporidiose, pode resultar em mortalidade e ocorre principalmente no período pós-desmame, quando há estresse relacionado à separação da mãe, ao transporte para gaiolas de engorda e à mudança de alimentação (Shiibashi et al., 2006; Kaupke et al., 2014).

No Brasil, não há trabalhos referentes à caracterização molecular de Cryptosporidium em coelhos. Em outros países, há diversos relatos de identificação de C. cuniculus e de seus subtipos relacionados ao gene da glicoproteína GP60 (Ryan et al., 2003; Chalmers et al., 2009; Nolan et al., 2010; Shi et al., 2010; Zhang et al., 2012; Kaupke et al., 2014).

Este trabalho visou determinar a ocorrência de Cryptosporidium spp. em amostras fecais de coelhos em granjas brasileiras, realizar sua caracterização molecular para determinação da espécie e do subtipo do parasito, bem como relacionar a presença do parasito às diferentes fases de criação.

\section{MATERIAL E MÉTODOS}

As amostras fecais foram colhidas em 21 criações comerciais de coelhos, que tem como objetivo a comercialização de animais de estimação para pesquisa, abate para consumo ou reprodução. As criações se localizam nos municípios de Bambuí (MG), São João Batista da Glória (MG), Campo Grande (MS), Jaboatão dos Guararapes (PE), Curitiba (PR), Teresópolis (RJ), Eldorado do Sul (RS), Porto Alegre (RS), Santa Maria (RS), Araçatuba (SP), Araraquara (SP), Botucatu (SP), Campinas (SP), Guariba (SP), Jaboticabal (SP), Pradópolis (SP), Ribeirão Pires (SP) e Ribeirão Preto (SP).

Foram colhidas 514 amostras, constituídas por aproximadamente $30 \mathrm{~g}$ de fezes, diretamente no interior das gaiolas, no piso embaixo das gaiolas ou em bandejas coletoras localizadas embaixo das gaiolas. As amostras foram armazenadas em frascos de plástico contendo dicromato de potássio $5 \%$, a $4^{\circ} \mathrm{C}$.

As amostras foram classificadas de acordo com a idade, o sexo e o estado reprodutivo dos animais: fêmeas não gestantes, fêmeas gestantes, fêmeas lactantes, filhotes de 31 a 50 dias de idade, filhotes de 51 a 80 dias de idade e machos adultos. As amostras de filhotes foram 
constituídas por um pool de amostras fecais referentes a vários animais alojados em uma mesma gaiola, enquanto as amostras de coelhos adultos foram individuais.

As amostras fecais foram coadas em peneira de plástico descartável e submetidas à concentração e purificação por centrífugo-flutuação em solução de Sheather acrescida com $0,1 \%$ de Tween 20. O sedimento resultante do processo de purificação foi diluído em solução salina fosfatada (PBS) com antibióticos (100U penicilina $/ \mathrm{mL}+100 \mu \mathrm{g}$ gentamicina $/ \mathrm{mL}+100 \mu \mathrm{g}$ estreptomicina $/ \mathrm{mL}+0,25 \mu \mathrm{g}$ anfotericina $\mathrm{B} / \mathrm{mL}$ ) e armazenado a $4^{\circ} \mathrm{C}$.

A pesquisa de oocistos de Cryptosporidium spp. foi realizada no sedimento resultante do processo de purificação das 514 amostras, utilizando-se a coloração negativa com verde malaquita (Elliot et al., 1999).

Para extração do DNA genômico de Cryptosporidium spp., foi utilizado um protocolo adaptado das técnicas descritas por Boom et al. (1990) e Wang et al. (2011). Os microtubos contendo o sedimento resultante da purificação foram centrifugados a $12.000 \mathrm{~g}$, por três minutos, com descarte do sobrenadante. O sedimento foi diluído em $600 \mu \mathrm{L}$ de tampão L1 (24g de isotiocianato de guanidina; $20 \mathrm{~mL}$ de Tris-HCL $0,1 \mathrm{M} \mathrm{pH} \mathrm{6,4;} \mathrm{4,4mL} \mathrm{de} \mathrm{EDTA} \mathrm{0,2M} \mathrm{pH} \mathrm{8,0;}$ $0,5 \mathrm{~mL}$ de Triton X-100 e polivinilpirrolidona $1 \%$ ). Após adição de $20 \mu \mathrm{L}$ de álcool isoamílico e $200 \mathrm{mg}$ de pérolas de vidro de $0,45 \mu \mathrm{m}$, o microtubo foi submetido à agitação por dois minutos, em velocidade máxima, no miniBeadbeater (Biospec, Estados Unidos), com incubação a $60^{\circ} \mathrm{C}$ por duas horas e agitação periódica a 1.000rpm por cinco segundos, a cada cinco minutos, e centrifugação a $12.000 \mathrm{~g}$ por cinco minutos. $\mathrm{O}$ sobrenadante foi homogeneizado com $300 \mu \mathrm{L}$ de isopropanol e transferido para uma coluna de sílica (ZymoSpin $^{\mathrm{TM}}$ IIIC, Zymo Research, Estados Unidos) previamente inserida em um tubo coletor de $2 \mathrm{~mL}$. O tubo foi centrifugado a $16.100 \mathrm{~g}$ por um minuto, com descarte da solução. Seiscentos microlitros de tampão L2 (24g de tiocianato de guanidina, $20 \mathrm{~mL}$ de $0,1 \mathrm{M}$ Tris-HCL $\mathrm{pH} 6,4$, $4,4 \mathrm{~mL}$ de EDTA $0,2 \mathrm{M} \mathrm{pH}$ 8,0) foram adicionados à coluna de sílica, com centrifugação a $16.100 \mathrm{~g}$, por um minuto, e descarte da solução. Seiscentos microlitros de tampão L3 (etanol 70\% em solução de $\mathrm{NaCl}$ $10 \mathrm{mM}$, Tris-HCL $10 \mathrm{mM}$ e EDTA $0,5 \mathrm{mM}, \mathrm{pH}$ 7,5) foram adicionados por duas vezes seguidas, com centrifugação a $16.100 \mathrm{~g}$, por um minuto, e descarte da solução do microtubo. Após transferência da coluna de sílica para um tubo de $1,5 \mathrm{~mL}, 50 \mu \mathrm{L}$ de solução de eluição (Tris $10 \mathrm{mM}$, EDTA 0,5mM, pH 9), previamente aquecida a $56^{\circ} \mathrm{C}$, foi adicionada à coluna de sílica, com centrifugação a $16.100 \mathrm{~g}$ por um minuto, colheita do DNA eluído e armazenamento a $-20^{\circ} \mathrm{C}$.

Para identificação da espécie de Cryptosporidium, 55 amostras foram selecionadas, de forma a que cada fase de criação fosse representada, incluindo as amostras positivas pela microscopia, para realização da reação em cadeia da polimerase (nested PCR) seguida de sequenciamento dos fragmentos amplificados (nested PCR/S). Dessa forma, foram selecionadas amostras correspondentes a cinco fêmeas não gestantes, 10 fêmeas gestantes, 12 fêmeas lactantes, 14 filhotes de 31 a 50 dias, oito filhotes de 51 a 80 dias e seis machos adultos.

A nested PCR foi realizada para amplificação de fragmentos do gene da subunidade $18 \mathrm{~S}$ do RNA ribossômico (18S rRNA), com os oligonucleotídeos iniciadores 5' TTCTAG AGCTAATACATGCG 3' e 5' CCCATTTCCTTCGAAACAGGA 3' para a reação primária (1325 pb) e 5' GGA AGG GTT GTA TTT ATT AGA TAA AG 3' e 5' AAG GAGTAAGGAACAACCTCCA 3' para a reação secundária $(826-840 \mathrm{pb})$ (Xiao et al., 2000).

Visando à subtipagem de $C$. cuniculus, as amostras positivas pela nested $\mathrm{PCR} / \mathrm{S}$ para $\mathrm{o}$ gene $18 \mathrm{~S}$ rRNA foram submetidas à nested $\mathrm{PCR} / \mathrm{S}$ para amplificação e sequenciamento de fragmento parcial do gene da glicoproteína GP60, utilizando-se os oligonucleotídeos iniciadores 5' ATAGTCTCCGCTGTATTC 3' e 5' GGAAGGAACGATGTATCT 3' para a reação primária $(909 \mathrm{bp})$ e 5 , TCCGCTGTATTCTCAGCC 3' e 5' GCAGAGGAACCAGCATC 3' para a reação secundária (875 pb) (Alves et al., 2003).

Como controle positivo da nested PCR, foi utilizado DNA genômico de Cryptosporidium serpentis (18S rRNA) e de C. parvum (GP60). 
Água ultrapura foi empregada como controle negativo. Os fragmentos amplificados foram visualizados por eletroforese em gel de agarose a $2 \%$ corado com brometo de etídio.

Os fragmentos resultantes da nested PCR para os dois genes foram purificados utilizando-se $\mathrm{o}$ QIAquick $^{\circledR}$ Gel Extraction kit (Qiagen, Alemanha) e submetidos ao sequenciamento bidirecional no Centro de Sequenciamento e Genômica Funcional da Unesp, Campus de Jaboticabal, utilizando-se o "ABI Prism ${ }^{\circledR}$ Dye Terminator 3.1" (Applied Biosystems, Estados Unidos), em sequenciador automático ABI 3730XL (Applied Biosystems, Estados Unidos).

A determinação das sequências consenso foi realizada por meio do software Codoncode Aligner v. 1.5.2. (CodonCode Corporation, Estados Unidos). As sequências consenso contendo nucleotídeos com valores de qualidade de sequenciamento maior ou igual a 20 foram alinhadas com auxílio dos programas Clustal W (Thompson et al., 1997) e BioEdit Sequence Alignment Editor (Hall, 1999), tomando-se como base sequências homólogas disponíveis no GenBank. As sequências de nucleotídeos descritas neste trabalho foram publicadas no Genbank, sob os códigos KT948753 e KT948754.

A análise estatística descritiva foi efetuada para avaliação dos resultados.

Este trabalho foi realizado após aprovação pelo Comitê de Ética no Uso de Animais das Faculdades de Odontologia e de Medicina Veterinária da Unesp, campus de Araçatuba, Processo FOA-00553-2013.

\section{RESULTADOS E DISCUSSÃO}

Pela microscopia e pela nested PCR, foi observada positividade para Cryptosporidium spp. de 1,56\% (8/514) e 12,73\% (7/55), respectivamente. Entre as amostras positivas pela microscopia, sete foram positivas pela nested PCR. Positividade para Cryptosporidium foi encontrada em cinco granjas, sendo três em amostras de filhotes de coelhos entre 31 e 50 dias, nas cidades de Campo Grande, Curitiba e Ribeirão Preto, duas de filhotes entre 51 e 80 dias, em Jaboticabal, uma de uma fêmea gestante e uma de uma fêmea lactante, em Ribeirão Preto (Tab. 1). A análise molecular revelou $C$. cuniculus para o gene $18 \mathrm{~S}$ rRNA e $C$. cuniculus subtipo VbA21 para o gene GP60, com 100\% de similaridade genética quando comparados às sequências publicadas no GenBank FJ262724 (gene 18S rRNA) e HQ397717 (gene GP60) (Tab. 1).

A criptosporidiose em coelhos geralmente se caracteriza por ausência de sinais clínicos e pelo baixo número de oocistos em fezes (Inman e Takeuchi, 1979; Pavlásek et al., 1996; Cox et al., 2005; Shiibashi et al., 2006). A enfermidade clínica ocorre com mais frequência em coelhos entre 30 e 40 dias de idade, e a fonte de infecção para os coelhos jovens são as mães que excretam oocistos pouco antes do parto e vários dias depois do parto (Pavlásek et al., 1996). Esses fatores podem explicar a ocorrência de $C$. cuniculus apenas em filhotes e em fêmeas gestantes e lactantes, como observado neste estudo.

Tabela 1. Identificação das amostras positivas para Cryptosporidium spp. pela nested PCR e pelo sequenciamento dos fragmentos amplificados, em relação à fase de criação

\begin{tabular}{cccc}
\hline Categoria & $\begin{array}{c}\text { PCR (gene 18S rRNA) } \\
\text { \% positivas (positivas/total) }\end{array}$ & $\begin{array}{c}\text { Sequenciamento } \\
\text { Gene 18S rRNA }\end{array}$ & $\begin{array}{c}\text { Sequenciamento } \\
\text { Gene GP60 }\end{array}$ \\
\hline Fêmea não gestante & $0(0 / 5)$ & - & - \\
Fêmea gestante & $10(1 / 10)$ & C. cuniculus & C. cuniculus VbA21 \\
Fêmea lactante & $8,33(1 / 12)$ & C. cuniculus & C. cuniculus VbA21 \\
Filhote $31-50$ dias & $21,43(3 / 14)$ & C. cuniculus & C. cuniculus VbA21 \\
Filhote 51-80 dias & $25(2 / 8)$ & C. cuniculus & C. cuniculus VbA21 \\
Machos & $0(0 / 6)$ & - & - \\
\hline
\end{tabular}


Ocorrência semelhante à encontrada neste estudo $(1,56 \% ; 8 / 514)$ foi observada no único trabalho desenvolvido no Brasil $(1,66 \% ; 2 / 120)$ que utilizou o exame microscópico para pesquisa de Cryptosporidium spp. em coelhos, no Rio Grande do Sul (Silva et al., 2006).

Em outros países, os valores de ocorrência de Cryptosporidium em coelhos também são semelhantes ao encontrado neste estudo, porém com identificação de outros subtipos relacionados ao gene GP60 (Chalmers et al., 2009; Nolan et al., 2010; Shi et al., 2010).

Zhang et al. (2012) relataram, em coelhos de quatro a seis meses de idade, na China, a presença dos subtipos VbA21e VbA32 de $C$. cuniculus e positividade para Cryptosporidium spp., pela microscopia, de 2,38\% (9/378). Shi et al. (2010) relataram prevalência de Cryptosporidium spp. de 3,4\% (37/1081) na China, sendo de $10,9 \%$ (27/249) para coelhos jovens e de 0,92\% (7/761) para coelhos adultos. Neste trabalho, considerando-se os animais por faixa etária, foi encontrada positividade de $22,73 \%(5 / 22)$ e de $5,71 \%(2 / 35)$ em coelhos jovens e em coelhos adultos, respectivamente. Ocorrência mais alta em coelhos jovens (19,7\%; 13/66) também foi identificada no Japão (Shiibashi et al., 2006).

O subtipo VbA21 também foi encontrado por Zhang et al. (2012) em granjas de coelhos na China. No entanto, não há relatos quanto à infecção pelo subtipo VbA21 em humanos, apesar de outros subtipos de C. cuniculus terem sido encontrados em humanos (Chalmers et al., 2009; Bouzid et al., 2010; Robinson e Chalmers, 2010).

Apesar de a ocorrência de infecção por $C$. cuniculus em criações brasileiras de coelhos pesquisadas neste experimento ser baixa e semelhante à observada em outros países, a possibilidade de transmissão de um agente zoonótico para o homem deve ser considerada, particularmente em pessoas que apresentam contado direto ou indireto com coelhos domésticos. Por outro lado, a infecção por C. cuniculus deve ser considerada no diagnóstico diferencial de enfermidade clínica relacionada ao sistema gastrintestinal em coelhos domésticos.

\section{CONCLUSÃO}

Os resultados deste estudo demonstram que o subtipo zoonótico VbA21 de C. cuniculus está presente em criações de coelhos no Brasil, em fêmeas gestantes, fêmeas lactantes e em filhotes.

\section{REFERÊNCIAS}

ALVES, M.; XIAO, L.; SULAIMAN, I. et al. Subgenotype analysis of Cryptosporidium isolates from humans, cattle, and zoo ruminants in Portugal. J. Clin. Microbiol., v.41, p.27442747, 2003.

BOOM, R.; SOL, C.J.; SALIMANS, M.M. et al. Rapid and simple method for purification of nucleic acids. J. Clin. Microbiol., v.28, p.495503, 1990.

BOUZID, M.; TYLER, K.M.; CHRISTEN, R. et al. Multilocus analysis of human infective Cryptosporidium species and subtypes using ten novel genetic loci. BMC Microbiol., v.10, p.213, 2010.

CHALMERS, R.M.; ROBINSON, G.; ELWIN, $\mathrm{K}$. et al. Cryptosporidium rabbit genotype, a newly identified human pathogen. Emerg. Infect. Dis., v.10, p.829-830, 2009.

COX, P.; GRIFFITH, M.; ANGLES, M. et al. Concentrations of pathogens and indicators in animal feces in the Sydney watershed. Appl. Environ. Microbiol., v.71, p.5929-5934, 2005.

DUSZYNSKI, D.W.; COUCH, L. (Eds.). The biology and identification of the Coccidia (Apicomplexa) of rabbits of the world. San Diego: Elsevier, 2013. 335p.

ELLIOT, A.; MORGAN, U.M.; THOMPSON, R.C. Improved staining method for detecting Cryptosporidium oocysts in stools using malachite green. J. Genet. Appl. Microbiol., v.45, p.139-142, 1999.

FAYER, R. Taxonomy and species delimitation in Cryptosporidium. Exp. Parasitol., v.124, p.9097, 2010.

HALL, T.A. BioEdit: a user-friendly biological sequence alignment editor and analysis program for Windows 95/98/NT. Nucleic Acids Symp. Ser., v.41, p.95-98, 1999. 
INMAN， L.R.; TAKEUCHI，A. Spontaneous cryptosporidiosis in an adult female rabbit. Vet. Pathol., v.16, p.89-95, 1979.

KAUPKE, A.; KWIT, E.; CHALMERS, R.M. et al. An outbreak of massive mortality among farm rabbits associated with Cryptosporidium infection. Res. Vet. Sci., v.97, p.85-87, 2014.

LIU, H.; SHEN, Y.; YIN, J. et al. Prevalence and genetic characterization of Cryptosporidium, Enterocytozoon, Giardia and Cyclospora in diarrheal out patients in China. BMC Infect. Dis., v.14, p.25, 2014.

MOSIER, D.A.; OBERST, R.D. Cryptosporidiosis: a global challenge. Ann. N. Y. Acad. Sci., v.916, p.102-111, 2000 .

NOLAN, M.J.; JEX, A.R.; HAYDON, S.R. et al. Molecular detection of Cryptosporidium cuniculus in rabbits in Australia. Infect. Genet. Evol., v.10, p.1179-1187, 2010.

PAVLÁSEK, I., LÁVICKA, M.; TUMOVÁ, E.; SKRIVAN, M. Spontaneous Cryptosporidium infection in weaned rabbits. Vet. Med., v.41, p.361-366, 1996.

ROBINSON, G.; CHALMERS, R.M. The European rabbit (Oryctolagus cuniculus), a source of zoonotic cryptosporidiosis. Zoonoses Public Health, v.57, p.e1-e13, 2010.

ROBINSON, G.; ELWIN, K.; CHALMERS, R.M. Unusual Cryptosporidium genotypes in human cases of diarrhea. Emerg. Infect. Dis., v.14, p.1800-1802, 2008.

RYAN, U.; XIAO, L.; READ, C. et al. Identification of novel Cryptosporidium genotypes from the Czech Republic. Appl. Environ. Microbiol., v.69, p.4302-4307, 2003.

SCALLAN, E.; HOEKSTRA, R.M.; ANGULO, F.J. et al. Foodborne illness acquired in the United States: major pathogens. Emerg. Infect. Dis., v.17, p.7-15, 2011.
SHI, K.; JIAN, F.; LV, C. et al. Prevalence, genetic characteristics, and zoonotic potential of Cryptosporidium species causing infections in farm rabbits in China. J. Clin. Microbiol., v.48, p.3263-3266, 2010.

SHIIBASHI, T.; IMAI, T.; SATO, Y. et al. Cryptosporidium infection in juvenile pet rabbits. J. Vet. Med. Sci., v.68, p.281-282, 2006.

SILVA, A.S.; CEOLIN, L.V.; MONTEIRO, S.G. Endoparasitoses de coelhos criados em diferentes sistemas de manejo. Rev. FZVA, v.13, p.127-136, 2006.

STRIEPEN, B. Time to tackle cryptosporidiosis. Nature, v.503, p.189-191, 2013.

THOMPSON, J.D.; GIBSON, T.J.; PLEWNIAK, F. et al. The Clustal $\mathrm{X}$ windows interface: flexible strategies for multiple sequence alignment aided by quality tools. Nucleic Acids Res., v.24, p.4876-4882, 1997.

WANG, T.Y.; WANG, L.; ZHANG, J.H. et al. A simplified universal genomic DNA extraction protocol suitable for PCR. Genet. Mol. Res., v.10, p.519-525, 2011.

XIAO, L. Molecular epidemiology of cryptosporidiosis: an update. Exp. Parasitol., v.124, p.80-89, 2010.

XIAO, L.; ALDERISIO, K.; LIMOR, J. et al. Identification of species and sources of Cryptosporidium oocysts in storm waters with a small-subunit rRNA-based diagnostic and genotyping tool. Appl. Environ. Microbiol., v.66, p.5492-5498, 2000 .

XIAO, L.; FAYER, R. Molecular characterisation of species and genotypes of Cryptosporidium and Giardia and assessment of zoonotic transmission. Int. J. Parasitol., v.38, p.1239-1255, 2008.

ZHANG, W.; SHEN, Y.; WANG, R. et al. Cryptosporidium cuniculus and Giardia duodenalis in rabbits: genetic diversity and possible zoonotic transmission. PloS One, v.7, p.e31262, 2012. 